\title{
Physical Attractiveness, Altruism and Cooperation in an Ultimatum Game
}

\author{
Manpal Singh Bhogal ${ }^{1} \&$ Niall Galbraith $^{1} \&$ Ken Manktelow ${ }^{1}$ \\ Manpal Singh Bhogal m.s.b2@wlv.ac.uk \\ Institute of Psychology, Faculty of Education, Health and Wellbeing, University of Wolverhampton, Millennium \\ City Building, City Campus, Wulfruna Street, Wolverhampton WV1 1SB, UK
}

\begin{abstract}
Explaining cooperative tendencies through an evolutionary lens has been problematic for theorists. Traditional explanations derive from theories of reciprocity, biological markets, and more recently via partner choice and sexual selection. The sexual selection hypothesis has been tested within game-theoretic frameworks gaining empirical sup- port in explaining the evolution of altruism. Males have been found to be more altruistic towards attractive females. However, previous research has predominantly adopted a design where participants are not engaging with 'real people'. Instead, participants make decisions when viewing images or hypothetical scenarios without visual cues. The present study aimed to investigate the sexual selection hypothesis using a face-to-face game theoretic framework. One hundred and thirty-eight participants played a 2-round ultimatum game with chocolate coins as the monetary incentive. We find, that physical attractiveness had no influence on generosity and cooperation when participants play a face-to-face ultimatum game. Instead, proposers were fair when allocating stakes, offering an average of half the endowment to responders. This study refutes the link between the sexual selection hypothesis and generosity when playing economic games with real people. Fairness appeared to drive generosity and cooperation.
\end{abstract}

Keywords Game theory · Ultimatum game · Sexual selection hypothesis · Fairness · Generosity Altruism

\section{Introduction}

Altruism $^{1}$ refers to an act which is beneficial to the receiver, yet costly for the altruist (Trivers 1971). Explaining the purpose of altruism has been a challenge within a variety of disciplines,

\footnotetext{
${ }^{1}$ Consistent with Barclay (2013) we use the terms altruism and generosity interchangeably. Both altruism and generosity confer benefits to a receiver whilst being costly to the altruist. Fairness is defined as equal sharing between giver and receiver (Baumard et al. 2013; Fehr and Schmidt 1999).
} 
particularly for evolutionary theorists. Where altruism towards kin is well-founded, altruism towards non-kin is an evolutionary puzzle (Hamilton 1963). Altruism has been explained by theories of reciprocity (Alexander 1987; Axelrod 1984), costly signaling (where altruism relays one's genetic quality, see Zahavi and Zahavi 1997) biological markets, (altruism evolves due to competitive mating markets, see Noe and Hammerstein 1995) and more recently via partner choice (people choose the most altruistic partners available within a mating market, see Barclay 2013) and sexual selection (altruism acts as a mating signal, see Farrelly et al. 2007; Phillips et al. 2008).

Recent research has tested the sexual selection hypothesis in explaining altruism within gametheoretic frameworks, typically via online simulations or using facial images. Although sexual selection has received empirical support in explaining the evolution of altruism, little research has investigated the sexual selection hypothesis when participants are engaging with real people, as opposed to facial images. This paper tests the sexual selection hypothesis, adopting a gametheoretic framework in a well-known game within game theory known as the ultimatum game.

\section{Altruism as a Mating Signal}

Nettle (2009) states that sexual selection is natural selection on the ability to gain mates ${ }^{\wedge}(\mathrm{p}$. 137). Darwin (1871) used sexual selection theory in an attempt to explain physical and behavioural traits which placed an organism at a survival disadvantage, yet providing a reproductive advantage. Examples include altruism and cooperation, which are costly to an individual's fitness. Darwin was well aware that some of these traits were more prevalent in one sex of a specie and not the other, used when attempting to attract the opposite sex.

The purpose of sexual selection is to maximise the chances of reproducing successfully and 
creating offspring through intra and inter-sexual competition. Darwin defined secondary sexual characteristics as 'the advantage which certain individuals have over other individuals of the same sex and species, in exclusive relation to reproduction' (Darwin 1871, p. 256). If a trait increases one's reproductive success, it is more prominent in the gene pool and more likely to be passed onto future generations (Nettle 2009). Workman and Reader (2014) eloquently refer to sexual selection as 'the survival of the sexiest' (p. 65).

Inter-sexual selection, ${ }^{2}$ often referred to as female-choice refers to traits which are not necessarily involved in survival per se, but they increase one's chances of being chosen as a mate. Inter-sexual competition predicts that it is males who should display ornaments to impress females as females need to be courted in order to consent to sexual engagement because they are the choosier sex (Brennan 2010; Workman and Reader 2014). Intra and inter-sexual competition then leads to sexual dimorphism, physical and behavioural differences be- tween the sexes. Therefore, altruism may have evolved through inter-sexual competition, detrimental to one's short term survival, but if overcome, beneficial to one's long-term mating encounters.

The sexual selection hypothesis suggests that the purpose of cooperation and altruism are to attract mates because they are sexually selectable traits (Miller 2000; Roberts 1998; Zahavi 1995). This may be because altruism signals commitment to- wards a partner and raises one's mate value in the mating market (Barclay 2010; Haselton and Buss 2000). Males typically use altruism as a courtship display to signal their quality as a partner (Tessman 1995). Because females place a greater importance on a male's ability to be gain resources, and males

\footnotetext{
${ }^{2}$ This paper concerns itself with inter-sexual competition, as opposed to intra-sexual competition. For further information on intra-sexual competition, see Workman and Reader (2014).
} 
value a female's physical attractiveness (Buss 1989), females should value altruistic and cooperative mates, more so than males (Barclay 2010). Females should value cooperative traits due to larger parental investment and increased likelihood that offspring will inherit cooperative tendencies (Anderson 1994). Parental investment theory suggests that human mate preferences have evolved due to differential investment each sex provides for offspring. Human females invest more than males into offspring, both biologically and through nurturing (Trivers 1972). However, males also offer a substantial level of parental investment in terms of resource acquisition and sharing (Kaplan and Hill 1985). Due to the value females place on cooperation and altruism in a mate, research has found that males exhibit altruistic and cooperative traits as courtship dis- plays, consistent with the sexual selection hypothesis (Barclay 2010; Farrelly et al. 2007; Goldberg 1995; Iredale et al. 2008; Miller 2000; Oda et al. 2011; Van Vugt and Iredale 2013). In support, traits which signal a male's cooperative tendencies are highly sought by females (Buss 1989; Miller 2000).

For females, choosing a cooperative mate increases the survival rate of future offspring (Spinath and O’Conner 2003; Kokko 1998). For a female, being choosy when selecting a mate is crucial as choosing a mate who does not possess cooperative tendencies increases the risk of abandonment and a lack of resources for future offspring. In order to test the sexual selection hypothesis in explaining altruism, it is important to investigate the factors which influence cooperation (Miller 2007).

We have discussed sexual selection as an explanation for the evolution of altruism. However, theories of competitive altruism (Roberts 1998), strong altruism and biological market theory have also received empirical interest. Recent models explaining altruism have incorporated partner choice (See Barclay 2013). Partner choice models assist in explaining how we choose the 
best mates available from the mating market, and the strategies we use to form relationships (Barclay 2016). Research has predominantly found that altruists are preferred as mates compared to non-altruists (Barclay 2010; Farrelly 2013). Biological markets theory (Noe and Hammerstein 1995) suggests that many traits and behaviours can be explained by market forces (Chiang 2010). As a result, people compete with others on traits such as altruism with an aim to increase their market value (Barclay 2016). Biological markets theory argues that partner choice is influenced by the perceived benefits of the qualities avail- able in the market pool from which one can choose a partner (Barclay 2013). These fitness benefits can be applied to oneself or one's offspring. According to biological markets, people should choose the most altruistic partners available in order to confer those benefits to oneself and future offspring. By choosing the best available, one has a selective advantage over others (see Barclay 2013 for a review).

\section{Physical Attractiveness, Game Theory and Altruism}

Behavioural game theory has been used extensively when investigating altruism and cooperation (see Camerer 2003; Fehr and Gachter 2002). Economic games enable us to test simple predictions and identify moderators of coopera- tive behaviour (Benenson et al. 2007; Cappelen et al. 2013). Game theoretic research has found that physical attractiveness may moderate how we distribute resources when playing economic games (Farrelly et al. 2007). Due to differences in parental investment, the sexes may differ in altruistic behaviour. For example, females tend to be more generous (Oswald et al. 2004) and kinder (Conway et al. 1996) than males (see Balliet et al. 2011 for a review).

Attractive people are treated more favourably than unattractive people in a number of domains, commonly known as the attractiveness halo effect (see Bak 2010; Dion et al. 1972; Langlois et 
al. 2000; Lorenzo et al. 2010; Maner et al. 2003). Physical attractiveness influences mate acquisition and reproductive success (Jokela 2009). Males and females are more generous and cooperative towards physically attractive people when playing economic games (e.g. Andreoni \& Petrie, 2008; Farrelly et al. 2007; Mulford et al. 1998; Solnick and Schweitzer 1999), in both developed and developing countries (McAndrew and Periloux 2012).

Moreover, males have been found to behave more generously towards attractive females (Eagly and Crowley 1986; Goldberg 1995; Iredale et al. 2008; Miller 2000) displaying higher levels of competitive altruism than females (Raihani and Smith 2015). People are also more trusting towards attractive people when playing economic games (Wilson and Eckel 2006). Self-rated attractiveness was also measured in this pa- per. Self-rated attractiveness has been found to influence how participants engage with one another when playing an economic game (see Stirrat et al. 2011). Males and females have been found to be more selfish towards those who are more attractive than themselves. Furthermore, self-rated attractive- ness has been found to be a predictor of attitudes towards inequality with those who consider themselves highly attractive being more agreeable on social inequality (Belmi and Neale 2014), which is also found in gametheoretical experiments (see Saad and Gill 2001).

\section{The Ultimatum Game}

The ultimatum game has been used extensively to measure cooperative tendencies in the laboratory (Kahneman et al. 1986; Larrick and Blount 1997; Straub and Mirninghan 1995; Wallace et al. 2007). The game is a simple economic game, measuring cooperation, generosity, fairness and selfishness. The game involves two players with each player assigned the role of proposer or responder. The game is played as follows: the proposer has a sum of money and has 
to decide how to split the money with the responder. If the responder rejects the offer made, both players leave empty handed (Falk and Fischbacher 2000). If the responder accepts, the game is complete. As we were interested in the influence of attractiveness on cooperation, we introduced a second round. When playing the ultimatum game, the rational strategy would be to maximise personal income and offer as little as possible to the other player. The proposer has the ability to be strategic when distributing an endowment, as offering more than the minimum is beneficial to the proposer, suggesting self-interest is a driver in ultimatum game behaviour (Roth et al. 1991).

Although extremely valuable, many experiments investigating the sexual selection hypothesis and generosity have involved hypothetical scenarios, facial images or online simulations (e.g. Barclay 2010; Rosenblat 2008; Shinada and Yamagishi 2014; Solnick and Schweitzer 1999). For example, Bhogal et al. (2016) conducted a study measuring the effects of physical attractiveness and sex on cooperative and generous behaviour in a sample of 187 participants. Using images as the static stimuli, they found that males reported significantly higher cooperativeness and generosity towards attractive females. Although females also reported higher cooperative tendencies towards attractive males, this effect was stronger for males. The above study forms a rationale, as we attempted to replicate the above findings in the present study, using an alternative experimental framework.

A limitation of the studies cited above is that they adopt methods that limit the physical cues available to participants, which can be remedied by adopting a face-to-face framework (Fontelle et al. 1985). Little research has investigated the role of physical attractiveness in gametheoretical situations where participants are playing with 'real people', as opposed to using photographs via online simulations. A further limitation of using photographs as opposed to faceto-face designs is that it limits the 'richness of each interaction' in game theoretic- research 
(Solnick and Schweitzer 1999, p. 201). It is our belief that face-to-face interactions provide the opportunity to study actual behaviour as much as possible within a laboratory setting.

This study aimed to investigate whether the proposer's perceived attractiveness of the responder, sex, and self- rated attractiveness influenced allocations made by the pro- poser. We hypothesised that proposers would be more generous (offer more coins) to participants they consider attractive. Therefore, we predicted that the perceived attractiveness of the recipient would significantly predict how many chocolate coins the proposer offers to the responder. In addition, we hypothesised that this effect would be stronger for males than females, as males display altruism as a courtship signal more often than females.

\section{Method}

Participants and Design One hundred and thirty-eight participants took part from the University of Wolverhampton (mean age $=21, \mathrm{SD}=2.67$ ). There were sixty-nine proposers (39 males, 30 females) and sixty-nine responders. Seventy- seven percent of the sample were single and $23 \%$ were dating. Due to reputation management effects observed in previous research (e.g. Andreoni and Bernheim 2009) participants were recruited from a variety of courses and campuses across the university. Proposers were randomly paired with opposite sex responders. As part of the screening process, only heterosexual participants were recruited due to the theoretical foundation

of the study. The predictor variables were the proposer's perceived attractiveness of the responder, self-rated attractive- ness and sex. The outcome was the number of chocolate coins offered to the responder. We used gold chocolate coins as the endowment. 
Materials and procedure ${ }^{3}$ Participants completed a questionnaire before and after playing the game, where they were asked for demographic details, how attractive they thought the other player was, and whether they would consider going on a date ${ }^{4}$ with the other player (all on a 1-7point Likert scale, $1=$ very unattractive, $7=$ very attractive). Participants then played an ultimatum game as follows; the proposer was given 10 chocolate coins to distribute with the responder. Each participant was given the role of proposer or responder. After the proposer made an offer, the responder accepted or rejected it. If the offer was accepted, both players kept their coins. If the responder rejected the offer, both players received no coins.

As generosity has been found to increase when being ob- served by an experimenter (see Milinski et al. 2002), the experimenter was not present whilst the game was being played, returning once the proposer signaled via a knock on the door. Once one round was complete (unknown to participants), the role of proposer and responder was counterbalanced and were provided with a further 10 chocolate coins to play another round (the experimenter again left the room and returned on completion of the second round). Upon completion, each participant completed the post-game questionnaire.

\section{Results}

${ }^{5}$ Multiple regression was conducted to assess the influence of the proposer's perceived attractiveness of the responder (pre-game), self-rated attractiveness and sex, on the number of chocolate coins offered to the responder. The total variance $\left(r^{2}\right)$ explained by the model was 4.4

\footnotetext{
${ }^{3}$ This study was approved by the University of Wolverhampton behavioural ethics committee. Informed consent was obtained from all individual participants included in the study.

${ }^{4}$ Due to high collinearity between the variables 'perceived attractiveness and dating intention', the dating intention item was taken out of the regression model.

${ }^{5}$ See published paper for tables
} 
$\%, \mathrm{~F}(3,65)=1.00, \mathrm{p}=.40, \mathrm{f}^{2}=.05$. The model, and predictor variables did not significantly predict offers made by the proposer. As a result, the experimental hypothesis was refuted. Beta values and descriptive statistics are present in Table 2.

\section{Logistic Regression}

Logistic regression was conducted to assess the impact of the responders' perceived attractiveness of the proposer (pre- game), self-rated attractiveness, sex and the number of chocolate coins offered by the proposer on whether the responder accepted or rejected those offers (96\% of responders accepted offers, $4 \%$ rejected). The model was statistically significant, $\chi^{2}(4, \mathrm{n}=69)=13.35, \mathrm{p}<.05$, explaining between $17.6 \%$ (Cox and Snell R square) and $58.5 \%$ (Nagelkerke R Square) in cooperation and correctly classifying $96 \%$ of cases. As shown in Table 3, none of the predictor variables made a significant contribution to the model. Again, the experimental hypotheses were refuted as cooperation was not influenced by sex, or the responders' perceived attractiveness of the proposer .

\section{Discussion}

The primary aim of this study was to investigate whether participants were more generous towards participants they considered attractive when playing an ultimatum game, a finding which has been found in previous game-theoretic research where participants are not engaging with real people. However, we found that when participants play an ultimatum allocated their stake. Participants may not have felt it to be equitable to offer more to those they found more attractive. Perhaps the role of fairness should be further research through an evolutionary lens. We know that self-interest can lead to fair behaviour (Chiang 2010), but we are still unaware of 
the evolutionary role of fairness in mate attraction, and signalling. Although fairness has been argued to have evolved through natural selection (see Gauthier, 1986; Rawls, 1971), it may serves a function in sexual selection and partner choice. Participants may have been fair to others because fairness signals one's moral character (Brosnan 2006). The findings are consistent with previous research where participants be- have fairly when distributing stakes (Li and Zhou 2014; Rand et al. 2013). Participants are motivated by and prefer equal outcomes (Andre and Baumard 2011; Fehr and Schmidt 1999). A number of experiments have found that fairness leads to positive evaluations (Moser et al. 2014). This study implies that fairness may play a role in intersexual competition as participants were fair, regardless of sex or attraction.

This study has some notable strengths. For example, traditional research investigating cooperation and defection has observed behaviour in virtual environments, which have largely been conducted online (Wischniewski et al. 2009). The obvious limitation of designs of this nature is the use of self-report data where no visual cues available. Using self- report data may elicit participant's ideal behaviour, rather than actual behaviour (Baldwin 1992; Fletcher and Kininmonth 1992). This study deals with this limitation by testing the sexual selection hypothesis in an alternate framework. Furthermore, an issue with using facial images when investigating altruism in the lab relates to the use of facial images only. Findings are then related to facial, as opposed to physical attractiveness (e.g. see Solnick and Schweitzer 1999).

There are some notable limitations of this research. For example, we did not test the hypotheses using a non- strategic game. The ultimatum game is an economic game driven by strategy (Eckel \& Grossman, 1998) as there was a risk to not being fair. If a proposer offers 2 out of 10 coins, the responder may not accept the offer leaving both empty hand- ed. Furthermore, there is also a social cost to not cooperating. Rejecting an offer reduces the likelihood of being chosen for 
future interactions with that person, and any of his or her game with a real person, people are not more generous to- wards those they are attracted to. As a result, our experimental hypothesis was rejected. We find no support for the sexual selection hypothesis in explaining the evolution of altruism in a game-theoretic setting. Instead, participants behaved fairly, regardless of how attractive they considered the other participant to be. Participants did not behave more altruistically towards those they found attractive. Furthermore, physical attractiveness did not influence whether responders accepted or rejected offers made by the proposer (cooperation). In sum, attractiveness had no influence on altruism and cooperation. The finding is inconsistent with previous research (e.g. Farrelly et al. 2007; Mulford et al. 1998) which may be due to methodological differences. Our study bypassed the typical method of using facial images and online simulations when investigating cooperative and generous behaviour.

Although we have not replicated the null finding reported in this paper by conducting a follow up experiment, our finding, that physical attractiveness has no influence on generosity, or cooperation, is consistent with previous research by Saad and Gill (2001). Saad and Gill conducted an experiment where participants played an ultimatum game in a face-to-face framework (consistent with the present study). They also found that physical attractiveness had no influence on generosity and cooperation. This supports the central theme of this paper; when participants play ultimatum games face-to-face, as opposed to using vignettes, facial images, and via online simulations, physical attractiveness does not influence generosity and cooperation. Instead, it appears that fairness drives allocation behaviour, which is an emerging theme from the findings reported in this study.

It appears that farness (offering on average half of the en- dowment to the responder) was a driver behind how proposers associates (Andre and Baumard 2011) leading to a lack of social 
opportunities (Aktipis 2004). This point may have presented itself as a limitation as behaviour was not simply influenced by how attractive the other person was, but was also dependent on how one could maximize his or her 'earnings' and whether or not a responder came across as being a 'good cooperator'. As a result, future research should investigate the sexual selection hypothesis using alternative economic games such as the dictator, trust, or the public goods game. Furthermore, we did not consider cultural influences on perceived attraction. Future research should test the sexual selection hypothesis as an explanation for altruism across a variety of cultures. Future research should also investigate social status and attraction towards fair or generous behaviour as social status can influence whether being altruistic is worth it, or not (Barclay 2016).

In sum, this paper extends previous research by providing evidence that attractiveness does not moderate generosity when playing a face-to-face ultimatum game. This study pro- vides evidence that alternate designs can produce varied results when investigating the sexual selection hypothesis.

Compliance with Ethical Standards There are no conflicts of interest. This research involved collecting data from human participants. Informed consent was taken from all participants who took part in this study. All procedures performed in studies involving human participants were in accordance with the ethical standards of the institutional and/or national research committee and with the 1964 Helsinki declaration and its later amendments or comparable ethical standards.

\section{References}

Aktipis, C. (2004). Know when to walk away: contingent movement and the evolution of cooperation. Journal of Theoretical Biology, 231(2), 249-260.

Alexander, R. D. (1987). The biology of moral systems. New York: Aldine De Grunter.

Anderson, M. (1994). Sexual selection. Princeton, NJ: Princeton University Press.

Andre, J., \& Baumard, N. (2011). Social opportunities and the evolution of fairness. Journal of Theoretical Biology, 289, 128-135. 
Andreoni, J., \& Bernheim, B. D. (2009). Social image and the 50-50 norm: a theoretical and experimental analysis of audience effects. Econometrica, 77(5), 1607-1636.

Andreoni, J., \& Petrie, R. (2008). Beauty, gender and stereotypes: Evidence from laboratory experiments. Journal of Economic Psychology, 29, 73-93.

Axelrod, R. (1984). The evolution of cooperation. New York: Basic.

Bak, P. M. (2010). Sex differences in the attractiveness halo-effect in the online dating environment. Journal of Business and Media Psychology, 1, 1-7.

Baldwin, M. W. (1992). Relational schemas and the processing of social information. Psychological Bulletin, 112, 461-484.

Balliet, D., Pi, N. P., Macfarlan, S. J., \& Van Vugt, M. (2011). Sex differences in cooperation: a meta-analytic review of social dilemmas. Psychological Bulletin, 137(6), 881-909.

Barclay, P. (2010). Altruism as a courtship display: some effects of third- party generosity on audience perceptions. The British Journal of Psychology, 101, 123-135.

Barclay, P. (2013). Strategies for cooperation in biological markets, especially for humans. Evolution and Human Behavior, 34(3), 164-175.

Barclay, P. (2016). Biological markets and the effects of partner choice on cooperation and friendship. Current opinions in Psychology, 7, 33-38.

Baumard, N., Andre, J., \& Sperber, D. (2013). A mutualistic approach to morality: the evolution of fairness by partner choice. Behavioral and

Brain Sciences, 36, 59-122. Belmi, P., \& Neale, M. (2014). Mirror, mirror on the wall, who's the fairest of them all? Thinking that one is attractive increases the tendency to support inequality. Organizational Behavior and Human Decision Processes, 124, 133-149.

Benenson, J. F., Pascoe, J., \& Radmore, N. (2007). Children's altruistic behaviour in the dictator game. Evolution and Human Behavior, 28, 168-175.

Bhogal, M. S., Galbraith, N., \& Manktelow, K. (2016). Sexual selection and the evolution of altruism: males are more altruistic and cooperative towards attractive females. Letters on Evolutionary Behavioral Science, 7(1), 10-13.

Brennan, P. (2010). Sexual selection. Nature Education Knowledge, 1, 24. Brosnan, S. F. (2006). Nonhuman species' reactions to inequity and their implications for fairness. Social Justice Research, 19, 153-185.

Buss, D. M. (1989). Sex differences in human mate preferences: evolutionary hypotheses testing in 37 cultures. Behavioral and Brain Sciences, 12, 1-49.

Camerer, C. F. (2003). Behavioral game theory: experiments in strategic interaction. Princeton: 


\section{University Press.}

Cappelen, A. W., Nielsen, U. H., Sorensen, E., Tungodden, B., \& Tyran, J.-R. (2013). Give and take in dictator games. Economic Letters, 118, 280-283.

Chiang, Y. (2010). Self-interested partner selection can lead to the emergence of fairness. Evolution and Human Behavior, 31(4), 265-270.

Conway, M., Pizzamiglio, M. T., \& Mount, L. (1996). Status, communality, and agency: implications for stereotypes of gender and other groups. Journal of Personality and Social Psychology, 71, 25-38.

Darwin, C. (1871). The descent of man, and selection in relation to sex. London: John Murray.

Dion, K., Berscheid, E., \& Walster, E. (1972). What is beautiful is good. Journal of Personality and Social Psychology, 24, 285-290.

Eagly, A. H., \& Crowley, M. (1986). Gender and helping behaviour: a meta-analytic review of the social psychological literature. Psychological Bulletin, 100(3), 283-308.

Eckel, C. C., \& Grossman, P, J. (1998). Are women less selfish than men? Evidence from dictator experiments. The Economic Journal, 108, 726-735.

Falk, A., \& Fischbacher, U. (2000). A theory of reciprocity. Institute for Empirical Economic Research. University of Zurich, working paper No. 6.

Farrelly, D. (2013). Altruism as an Indicator of Good Parenting Quality in Long-Term Relationships: Further Investigations Using the Mate Preferences Towards Altruistic Traits Scale. The Journal of Social Psychology, 153(4), 395-398.

Farrelly, D., Lazarus, J., \& Roberts, G. (2007). Altruists attract. Evolutionary Psychology, 5(2), 313-329.

Fehr, E., \& Gachter, S. (2002). Altruistic punishment in humans. Nature, 415, 137-140.

Fehr, E., \& Schmidt, K. M. (1999). A theory of fairness, competition, and cooperation. Quarterly Journal of Economics, 114, 817-868.

Fletcher, G. J. O., \& Kininmonth, L. A. (1992). Measuring relationship beliefs: an individual differences scale. Journal of Research in Personality, 26, 371-397.

Fontelle, G. A., Phillips, A. P., \& Lane, D. (1985). Generalising across stimuli as well as subjects: a neglected aspect of external validity. Journal of Applied Psychology, 70(1), 101-107.

Gauthier, D. (1986). Morals by agreement. Oxford, New York: Clarendon Press; Oxford University Press. 
Goldberg, T. L. (1995). Altruism towards panhandlers: who gives? Human Nature, 6, 79-89.

Hamilton, W. D. (1963). The evolution of altruistic behavior. American Naturalist, 97, 354-356.

Haselton, M., \& Buss, D. M. (2000). Error management theory: a new perspective on biases in cross-sex mind reading. Journal of Personality and Social Psychology, 78, 81-91.

Iredale, W., Van Vugt, M., \& Dunbar, R. (2008). Showing off in humans: Male generosity as a mating signal. Evolutionary Psychology, 6, 386-392.

Jokela, M. (2009). Physical attractiveness and reproductive success in humans: evidence from the late 20th century United States. Evolution and Human Behavior, 30, 342-350.

Kahneman, D., Knetsc, J. L., \& Thaler, R. H. (1986). Fairness and the assumptions of economics. Journal of Business, 59(4), 5825-5300.

Kaplan, H., \& Hill, K. (1985). Food sharing among ache foragers: tests of explanatory hypotheses. Current Anthropology, 26, 223-246.

Kokko, H. (1998). Should advertising parental care be honest? Proceedings of the Royal Society of London B, 265, 1871-1878.

Langlois, J. H., Kalakanis, L., Rubenstein, A. J., Larson, A., Hallam, M., \& Smoot, M. (2000). Maxims or myths of beauty? A meta-analytic and theoretical review. Psychological Bulletin, 26, 390-423.

Larrick, R. P., \& Blount, S. (1997). The claiming effect: why players are more generous in social dilemmas than in ultimatum games. Journal of Personality and Social Psychology, 72(4), $810-825$.

Li, J., \& Zhou, X. (2014). Sex, attractiveness, and third-party punishment in fairness consideration. PloS One, 9(4), e94004.

Lorenzo, G. L., Biesanz, J. C., \& Human, L. J. (2010). What is beautiful if good and more accurately understood: physical attractiveness and accuracy in first impressions of personality. Association for Psychological Science, 21(12), 1777-1782.

Maner, J. K., Kenrick, D. T., Becker, D. V., Delton, A. W., Hofer, B., Wilbur, C., \& Neuberg, S. (2003). Sexually selective cognition: beauty captures the mind of the beholder. Journal of Personality and Social Psychology, 85, 1107-1120.

McAndrew, F. T., \& Periloux, C. (2012). Is self-sacrificial competitive altruism primarily a male activity? Evolutionary Psychology, 10(1), 50-65.

Milinski, M., Semmann, D., \& Krambeck, H. J. (2002). Reputation helps solve the 'strategy of the commons'. Nature, 415, 424-426.

Miller, G. (2000). The mating mind: how sexual choice shaped the evolution of human nature. 
New York: Penguin.

Miller, G. F. (2007). Sexual selection for moral virtues. Quarterly Review of Biology, 82, 97125.

Moser, A., Gaertig, C., \& Ruz, M. (2014). Social information and personal interests modulate neural activity during economic decision- making. Frontiers of Human Neuroscience., 8, 31.

Mulford, M., Orbell, J., Shatto, C., \& Stockard, J. (1998). Physical attractiveness, opportunity, and success in everyday exchange. American Journal of Sociology, 103(6), 1565-1592.

Nettle, D. (2009). Evolution and genetics for psychology. Oxford University Press.

Noe, R., \& Hammerstein, P. (1995). Biological markets. Trends in Ecology and Evolution, 10, 336-339.

Oda, R., Niwa, Y., Honma, A., \& Hiraishi, K. (2011). An eye-like painting enhances the expectation of a good reputation. Evolution and Human Behavior, 32(3), 166-171.

Oswald, D. L., Clark, E. M., \& Kelly, C. M. (2004). Friendship maintenance: an analysis of individual and dyad behaviors. Journal of Social and Clinical Psychology, 23(3), 413441 .

Phillips, T., Barnard, C., Ferguson, E., \& Reader, T. (2008). Do humans prefer altruistic mates? Testing a link between sexual selection and altruism towards non-relatives. British Journal of Psychology, 99, 555-572.

Raihani, N. J., \& Smith, S. (2015). Competitive helping in online giving. Current Biology, 25(9), $1183-1186$.

Rand, D. G., Tarnita, C. E., Ohtsuki, H., \& Nowak, M. A. (2013). Evolution of fairness in the one-shot anonymous ultimatum game. Proceedings of the National Academy of Sciences, 110(7), 2581-2586.

Rawls, J. (1971). A theory of justice. Cambridge, Mass: Belknap Press of Harvard University Press.

Roberts, G. (1998). Competitive altruism: From reciprocity to the handicap principle. Proceedings of the Royal Society of London, 265, 427-431.

Rosenblat, T. S. (2008). The beauty premium: physical attractiveness and gender in dictator games. Negotiation Journal, 24(4), 465-481.

Roth, A. E., Prasnikar, V., Okuno-Fujiwara, M., \& Zamir, S. (1991). Bargaining and market behaviour in Jerusalem, Ljubljana, Pittsburgh, and Tokyo: an experimental study. American Economic Review, 81, 1068-1095. 
Saad, D., \& Gill, T. (2001). Sex differences in the ultimatum game: an evolutionary psychology perspective. Journal of Bioeconomics, 3, 171-193.

Shinada, M., \& Yamagishi, T. (2014). Physical attractiveness and coop- eration in a prisoner's dilemma game. Evolution and Human Behavior, 35, 451-455.

Solnick, S. J., \& Schweitzer, M. E. (1999). The influence of physical attractiveness and gender on ultimatum game decisions. Organizational Behavior and Human Decision Processes, 79(3), 199-215.

Spinath, F. M., \& O'Conner, T. G. (2003). A behavioural genetic study of the overlap between personality and parenting. Journal of Personality, 71, 785-808.

Stirrat, M., Gumert, M., \& Perrett, D. (2011). The effect of attractiveness on food sharing preferences in human mating markets. Evolutionary Psychology, 9, 79-91.

Straub, P. G., \& Mirninghan, J. K. (1995). An experimental investigation of ultimatum games: information, fairness, expectations, and lowest acceptable offers. Journal of Economic Behavior and Organization, 27(3), 345-364.

Tessman, I. (1995). Human altruism as a courtship display. Oikos, 74, 157-158.

Trivers, R. L. (1971). The evolution of reciprocal altruism. Quarterly Review of Biology, 46, 3557.

Trivers, R. L. (1972). Parental investment and sexual selection. In B. Campbell (Ed.), Sexual selection and the descent of man, 1871- 1971 (pp. 136-179). Chicago: Aldine.

Van Vugt, M., \& Iredale, W. (2013). Men behaving nicely: public goods as peacock tails. British Journal of Psychology, 104, 3-13.

Wallace, B., Cesaeini, D., Lichtenstein, P., \& Johannesson, M. (2007). Heritability of ultimatum game responder behaviour. Proceedings of the National Academy of Sciences, 104(40), $15631-15634$.

Wilson, R. K., \& Eckel, C. C. (2006). Judging a book by its cover: beauty and expectations in the trust game. Political Research Quarterly, 59, 189-202.

Wischniewski, J., Windmann, S., Juckel, G., \& Brune, M. (2009). Rules of social exchange: game theory, individual differences and psycho- pathology. Neuroscience and Biobehavioral Reviews, 33, 305-313.

Workman, L., \& Reader, W. (2014). Evolutionary Psychology (3rd edn). Cambridge University Press.

Zahavi, A. (1995). Altruism as a handicap-the limitations of kin selection and reciprocity. Journal of Avian Biology, 26, 1-3. 
Zahavi, A., \& Zahavi, A. (1997). The handicap principle: A missing part of Darwin's puzzle. Oxford: Oxford University Press. 